OPEN ACCESS

Edited by:

Anshul Saxena,

Florida International University,

United States

Reviewed by:

Abdelbaset Mohamed Elasbali,

Al Jouf University, Saudi Arabia

Hamideh Salimzadeh,

Tehran University of Medical

Sciences, Iran

*Correspondence:

Mehdi Mirsaeidi

msm249@miami.edu

Specialty section:

This article was submitted to Cancer Epidemiology and Prevention,

a section of the journal

Frontiers in Oncology

Received: 28 May 2020

Accepted: 08 July 2020

Published: 21 August 2020

Citation:

Lee Y-C, Calderon-Candelario RA,

Holt GE, Campos MA and Mirsaeidi M (2020) State-Level Disparity in Lung

Cancer Survival in the United States.

Front. Oncol. 10:1449.

doi: 10.3389/fonc.2020.01449

\section{State-Level Disparity in Lung Cancer Survival in the United States}

\author{
Yu-Che Lee ${ }^{1,2,3}$, Rafael A. Calderon-Candelario ${ }^{1,2}$, Gregory E. Holt ${ }^{1,2}$, \\ Michael A. Campos ${ }^{1,2}$ and Mehdi Mirsaeidi ${ }^{1,2,3 *}$ \\ ${ }^{1}$ Division of Pulmonary and Critical Care Medicine, University of Miami Miller School of Medicine, Miami, FL, United States, \\ ${ }^{2}$ Section of Pulmonary Medicine, Miami Veterans Affairs Healthcare System, Miami, FL, United States, ${ }^{3}$ Department of \\ Public Health Sciences, University of Miami Miller School of Medicine, Miami, FL, United States
}

Rationale: The cancer mortality-to-incidence ratio (MIR) can serve as a population-based indicator for cancer care outcomes. In the US, evaluation of lung cancer survival by individual states has not been evaluated.

Objective: To assess the association between lung cancer survival by using MIRs and state-level health disparities in the United States.

Methods: We calculated 5-year lung cancer MIR averages from 2011 to 2015 using the United States Cancer Statistics (USCS) data. America's Health Rankings (AHR) is a platform using weighted measures in five different categories to calculate annual state health rankings. Five-year averages from 2011 to 2015 of the health uninsured rate and 4-year averages from 2011 to 2014 of health spending per capita were obtained from the U.S. Census Bureau and Centers for Medicare \& Medicaid Services. Linear regression analyses were performed to determine the associations between cancer survival value $(\mathrm{CSV})=(1-\mathrm{MIR}) \times 100 \%$ and state health variables

Results: During the study period, the 5-year averages of age-adjusted incidence, mortality rates, and CSVs were $60.3 \pm 2.1$ per 100,000 population, $43.4 \pm 2.1$ per 100,000 , and $27.9 \pm 3.9 \%$, respectively. Among the 50 states, Connecticut had the highest CSV (38.6 $\pm 1.7 \%)$ whereas Nevada had the lowest CSV (18.7 $\pm 6.5 \%)$. Hawaii had the highest health ranking and Mississippi had the lowest ranking in 2016. States with better health rankings, lower health uninsured rates, and higher health spending were significantly associated with higher CSVs $\left(R^{2}=0.418, P<0.001 ; R^{2}=0.352, P\right.$ $<0.001 ; R^{2}=0.142, P=0.007$, respectively).

Conclusions: There are significant differences in lung cancer survival within the United States. Lung cancer survival by using CSV was strongly associated with state health disparities, and it can be an applicable measure to evaluate the state-level health disparities in the United States.

Keywords: lung cancer survival, America's Health Rankings, health economy (source: MeSH NLM), insurance, disparity 


\section{INTRODUCTION}

Lung cancer is the second most commonly diagnosed cancer and the leading cause of cancer deaths in the United States (US). Approximately 228,150 new cases of lung cancer and 142,670 lung cancer deaths are expected to occur in the US in 2019 (1). However, favorable epidemiologic trends have been observed in the last decade. From 2011 to 2015, lung cancer incidence rates decreased gradually likely due to improved tobacco control and smoking cessation (2). Lung cancer mortality rates have also decreased due to reductions in smoking, improvements in early detection by low-dose spiral computed tomography (LDCT), and therapeutic advances such as improvements in minimally invasive surgery, novel chemotherapies, and biomarker-driven drugs (targeted therapies and immunotherapies) (2-4).

Racial and gender disparities in lung cancer incidence and mortality rates have been well-described, attributed not only to variations in risk factors (smoking rates) but also to variable access to screening and overall quality of care $(1,3)$. By estimating cancer mortality accounting for its incidence, the cancer mortality-to-incidence ratio (MIR) provides a populationbased indicator of cancer survival and is a useful parameter to evaluate cancer control programs (5-7). In this way, MIR has been used to evaluate and compare differences in cancer health outcomes between health care systems worldwide, showing strong inverse correlations between cancer MIRs and the quality of health care systems (8-12). For example, for lung cancer, every 1-unit change (worsening) in health system ranking was associated with a 0.004 increment rise in MIR (9). Countries with the highest MIR included Sweden, Italy, Chile, and Estonia, while countries with lower MIR included Slovak Republic, Czech Republic, Australia, and the United States.

Despite the lower overall MIR in the US, health delivery and quality of care are not uniform as significant differences in health delivery outcomes have been described at the state level in terms of health uninsured rates and health spending per capita (13). We hypothesize that state variation in lung cancer MIR will be correlated with state's health rankings because of prior crosscountry studies (8-12), with the health uninsured rate because of lower use of preventive screenings and later stage diagnoses, and with health spending per capita because of lower use of expensive new curative procedures. Therefore, the aim of this study was to analyze the association of these variable state health delivery parameters and lung cancer outcomes by using MIRs to provide another perspective of the impact of state-level health disparities in the United States.

\section{MATERIALS AND METHODS}

\section{Data Sources}

Age-adjusted mortality and incidence rates per 100,000 population per year were obtained from the United States Cancer Statistics (USCS) database provided by the Centers

Abbreviations: AHR, America's Health Rankings; CSV, cancer survival value; LDCT, low-dose spiral computed tomography; MIR, mortality-to-incidence ratio; OECD, Organization for Economic Co-operation and Development. for Disease Control and Prevention (CDC). MIR calculations were performed by dividing the age-adjusted mortality rate by the age-adjusted incidence rate per 100,000. With these data, we calculated 5-year averages from 2011 to 2015 for all 50 states. We defined the statistic, cancer survival value (CSV) as $(1-$ MIR $) \times 100 \%$ where values approaching $0 \%$ represent a poor survival rate and those approaching $100 \%$ represent an excellent survival rate. America's Health Rankings (AHR) was created as a partnership between the United Health Foundation and the American Public Health Association. AHR evaluates the factors that influence health outcomes and determine the state's health rankings since 1990. The numerical health ranking was calculated for each state in the year 2016 by an equation using weighted measures in five different categories: $25 \%$ for Behaviors, $22.5 \%$ for Community \& Environment, $12.5 \%$ for Policy, $15 \%$ for Clinical Care, and 25\% for Outcomes. In addition, 5-year averages of health uninsured rate by state from 2011 to 2015 were obtained from the U.S. Census Bureau and 4-year averages of health spending per capita by state from 2011 to 2014 were obtained from Centers for Medicare \& Medicaid Services.

\section{Statistical Analyses}

Scatterplots of state health rankings, health uninsured rates by state, and health spending per capita by state vs. CSV were generated, respectively. The association between CSVs and state health variables was calculated by three separate univariate linear regression analyses with the following formulas: $\mathrm{CSV}=$ State Health Ranking * Beta + Alpha; CSV $=$ Health Uninsured Rates * Beta + Alpha; CSV $=$ Health Spending per capita * Beta + Alpha. All data management and statistical analyses were performed in Microsoft Excel and Statistics Software SAS ${ }^{\circledR}$. $P<0.05$ using two-sided $t$ tests were considered statistically significant.

\section{RESULTS}

\section{Lung Cancer Incidence, Mortality Rates, and CSVs by State}

We first examined lung cancer statistics in the United States by analyzing the average age-adjusted incidence, mortality rates, and CSVs from 2011 to 2015. During this period, a total of $1,087,810$ people were diagnosed with lung cancer and 779,796 people died from lung cancer. The overall 5-year average of age-adjusted incidence, mortality rates, and CSVs were $60.3 \pm 2.1$ per 100,000 population, $43.4 \pm 2.1$ per 100,000 , and $27.9 \pm 3.9 \%$, respectively. The analysis based on 50 states indicated that Kentucky had the highest age-adjusted incidence and mortality rate $(93.5 \pm 2.4$ and $67.8 \pm 2.2$ per 100,000 , respectively), whereas Utah had the lowest age-adjusted incidence and mortality rate $(27.7 \pm 2.4$ and $19.5 \pm$ 0.7 per 100,000, respectively). Regarding CSVs, Connecticut had the highest CSV $(38.6 \pm 1.7 \%)$ and Nevada had the lowest CSV $(18.7 \pm 6.5 \%)$. The results are summarized in Table 1 and shown in Figures 1, 2. 
TABLE 1 | Summary of state health rankings, age-adjusted incidence and mortality rate, cancer survival value (CSV) for lung cancer, health uninsured rate, and health spending per capita of 50 states.

\begin{tabular}{|c|c|c|c|c|c|c|c|}
\hline \multirow[t]{2}{*}{ State } & \multirow[t]{2}{*}{$\begin{array}{l}2016 \text { America's } \\
\text { Health Rankings } \\
\text { (AHR) }\end{array}$} & \multicolumn{2}{|c|}{$\begin{array}{c}\text { 2011-2015 } \\
\text { Five-Year Average of } \\
\text { Age-Adjusted Rate per } 100,000\end{array}$} & \multicolumn{2}{|c|}{$\begin{array}{c}\text { 2011-2015 } \\
\text { Cancer Survival Value (\%) }\end{array}$} & \multirow{2}{*}{$\begin{array}{c}\text { 2011-2015 } \\
\text { Five-Year Average } \\
\text { of Health } \\
\text { Uninsured } \\
\text { Percentage } \\
\text { (Standard } \\
\text { Deviation) }\end{array}$} & \multirow{2}{*}{$\begin{array}{c}\text { 2011-2014 } \\
\text { Four-Year Average } \\
\text { of Health Spending } \\
\text { Per Capita, Dollars } \\
\text { per Year } \\
\text { (Standard } \\
\text { Deviation) }\end{array}$} \\
\hline & & $\begin{array}{l}\text { Incidence } \\
\text { (Standard } \\
\text { Deviation) }\end{array}$ & $\begin{array}{l}\text { Mortality } \\
\text { (Standard } \\
\text { Deviation) }\end{array}$ & $\begin{array}{l}\text { Mean } \\
\text { (Standard } \\
\text { Deviation) }\end{array}$ & $\begin{array}{l}\text { Median } \\
\text { (Interquartile } \\
\text { Range) }\end{array}$ & & \\
\hline Hawaii & 1 & $46.2(2.5)$ & $31.6(1.5)$ & $31.4(4.1)$ & 29.8 (27.8-35.9) & $6.0(1.3)$ & 6,896.0 (321.8) \\
\hline Massachusetts & 2 & $63.8(1.9)$ & $42.1(2.5)$ & $34.0(2.0)$ & 34.1 (32.1-35.9) & $3.6(0.6)$ & $10,180.3$ (313.7) \\
\hline Connecticut & 3 & $61.0(2.5)$ & $37.5(2.1)$ & $38.6(1.7)$ & $39.3(37.1-39.7)$ & $8.0(1.5)$ & $9,406.5$ (381.5) \\
\hline Minnesota & 4 & $55.2(1.9)$ & $38.8(1.0)$ & $29.6(4.0)$ & 29.5 (25.8-33.4) & $7.1(1.8)$ & 8,370.3 (391.1) \\
\hline Vermont & 5 & $63.5(3.1)$ & 44.8 (3.6) & $29.5(4.1)$ & 30.0 (25.8-33.0) & $5.8(1.4)$ & $9,571.3$ (595.1) \\
\hline New Hampshire & 6 & $65.8(3.4)$ & $45.7(3.9)$ & $30.6(4.0)$ & $29.9(27.8-33.7)$ & $9.5(1.9)$ & 9,193.0 (361.1) \\
\hline Washington & 7 & $56.9(3.1)$ & $40.7(2.4)$ & $28.4(1.7)$ & 28.5 (26.8-30.0) & $11.6(3.5)$ & 7,525.5 (329.9) \\
\hline Utah & 8 & $27.7(2.4)$ & $19.5(0.7)$ & $29.4(3.7)$ & 29.7 (25.7-33.0) & $13.4(1.9)$ & 5,631.0 (268.2) \\
\hline New Jersey & 9 & $57.4(1.8)$ & $38.4(2.4)$ & $33.2(2.2)$ & $33.5(31.2-35.1)$ & $11.7(1.9)$ & 8,379.8 (380.1) \\
\hline Colorado & 10 & $43.4(2.1)$ & $30.3(2.1)$ & $30.2(1.6)$ & 30.5 (28.9-31.4) & $12.5(3.1)$ & 6,427.8 (287.3) \\
\hline North Dakota & 11 & $58.3(2.4)$ & $39.6(3.2)$ & $32.2(3.8)$ & 32.0 (28.5-36.0) & $9.2(1.2)$ & $9,242.8(481.6)$ \\
\hline Nebraska & 12 & $59.0(2.2)$ & $42.3(0.9)$ & $28.3(1.7)$ & 27.9 (27.1-29.9) & $10.4(1.4)$ & 8,059.8 (291.4) \\
\hline New York & 13 & $60.2(1.7)$ & $39.0(2.3)$ & $35.3(2.5)$ & $34.4(33.4-37.7)$ & $9.8(1.8)$ & 9,305.3 (347.3) \\
\hline Rhode Island & 14 & $69.6(2.5)$ & $48.3(1.3)$ & $30.6(2.5)$ & 32.2 (28.1-32.3) & $9.3(2.6)$ & 9,113.5 (330.0) \\
\hline Idaho & 15 & $50.8(1.8)$ & $36.2(1.2)$ & $28.8(2.3)$ & 28.8 (26.7-30.9) & $14.7(2.4)$ & 6,508.8 (335.8) \\
\hline California & 16 & $43.4(1.8)$ & $32.2(1.9)$ & $25.8(1.5)$ & $25.9(24.5-27.1)$ & $14.8(4.2)$ & $7,140.0(345.5)$ \\
\hline lowa & 17 & $63.6(0.7)$ & $45.6(1.6)$ & $28.3(3.0)$ & $27.0(26.6-30.8)$ & $7.3(1.7)$ & 7,767.5 (329.8) \\
\hline Maryland & 18 & $57.5(1.6)$ & $41.6(2.5)$ & $27.6(2.8)$ & $26.3(25.5-30.4)$ & $9.1(1.7)$ & $8,226.0(281.5)$ \\
\hline Virginia & 19 & $58.9(2.8)$ & $44.1(2.6)$ & $25.1(2.0)$ & 25.9 (23.4-26.6) & $11.5(1.5)$ & 7,221.0 (284.9) \\
\hline Wisconsin & 20 & $60.0(2.0)$ & $43.0(2.7)$ & $28.3(2.2)$ & $28.4(26.5-30.1)$ & $8.0(1.5)$ & 8,230.8 (326.7) \\
\hline Oregon & 21 & $56.4(4.9)$ & $42.5(3.2)$ & $24.6(3.0)$ & $25.9(21.4-27.2)$ & $12.4(3.8)$ & $7,400.3$ (476.9) \\
\hline Maine & 22 & 72.6 (2.9) & $51.6(2.8)$ & $28.9(3.2)$ & 27.8 (26.5-32.0) & $10.1(1.1)$ & 9,122.3 (300.5) \\
\hline Montana & 23 & $55.8(3.6)$ & $41.2(4.0)$ & $26.2(6.1)$ & 24.6 (21.3-31.9) & $15.7(2.8)$ & 7,790.3 (403.1) \\
\hline South Dakota & 24 & $58.1(2.0)$ & $42.9(2.7)$ & 26.1 (5.3) & $26.0(21.5-30.7)$ & $10.9(0.9)$ & 8,470.0 (366.3) \\
\hline Wyoming & 25 & $44.6(3.7)$ & $35.3(2.9)$ & $20.6(7.4)$ & $22.2(13.9-26.5)$ & $13.5(1.8)$ & 7,917.0 (317.9) \\
\hline Illinois & 26 & $66.1(1.9)$ & $46.4(2.0)$ & $29.8(1.6)$ & $29.1(28.5-31.4)$ & $11.1(2.6)$ & 7,816.8 (356.1) \\
\hline Kansas & 27 & $60.9(1.9)$ & $45.9(1.5)$ & $24.6(3.2)$ & 24.5 (22.0-27.2) & $11.4(1.6)$ & 7,427.3 (206.8) \\
\hline Pennsylvania & 28 & $64.7(1.6)$ & $45.3(1.9)$ & $30.1(1.6)$ & 30.6 (28.5-31.5) & $8.9(1.5)$ & 8,799.8 (355.6) \\
\hline Arizona & 29 & $49.5(2.5)$ & $35.4(1.6)$ & $28.5(2.2)$ & $29.2(26.2-30.4)$ & $15.3(3.0)$ & 6,243.3 (158.7) \\
\hline Alaska & 30 & $57.5(4.7)$ & $46.2(4.6)$ & $19.5(5.9)$ & 20.5 (13.6-25.0) & $18.2(2.3)$ & 10,302.0 (616.1) \\
\hline Delaware & 31 & $71.2(3.1)$ & $48.9(3.1)$ & $31.2(3.9)$ & 32.3 (28.1-33.9) & $8.2(1.4)$ & $9,666.5$ (452.9) \\
\hline North Carolina & 32 & $69.3(1.4)$ & $49.1(2.5)$ & $29.2(2.6)$ & $29.4(26.9-31.4)$ & $14.6(2.3)$ & 7,043.0 (187.3) \\
\hline Texas & 33 & $53.2(2.6)$ & $39.1(2.9)$ & $26.6(2.2)$ & $27.2(24.7-28.2)$ & $20.8(2.5)$ & 6,636.5 (278.4) \\
\hline Michigan & 34 & $65.6(2.5)$ & $48.6(1.9)$ & $26.0(0.3)$ & $26.0(25.7-26.3)$ & $9.8(2.4)$ & 7,710.8 (269.6) \\
\hline Nevada & 35 & $56.4(6.7)$ & $45.5(2.5)$ & $18.7(6.5)$ & $22.4(11.8-23.8)$ & $18.5(4.5)$ & 6,243.5 (341.9) \\
\hline Florida & 36 & 59.8 (3.5) & $42.5(2.1)$ & $28.9(1.2)$ & 29.2 (27.9-29.9) & $18.2(3.2)$ & 7,701.8 (277.5) \\
\hline Missouri & 37 & $74.3(2.4)$ & $54.1(1.9)$ & $27.1(0.7)$ & 27.0 (26.5-27.9) & $12.4(1.6)$ & 7,791.5 (275.8) \\
\hline New Mexico & 38 & $40.3(1.6)$ & $30.6(1.2)$ & $24.0(2.5)$ & $24.2(21.7-26.2)$ & $16.4(3.7)$ & 6,853.0 (270.1) \\
\hline Indiana & 39 & $72.9(1.6)$ & $53.5(1.9)$ & $26.6(2.6)$ & $25.8(24.4-29.1)$ & $12.9(2.1)$ & 7,839.3 (418.5) \\
\hline Ohio & 40 & $69.4(1.9)$ & $51.8(2.5)$ & $25.4(2.2)$ & $25.6(23.3-27.4)$ & $9.9(2.3)$ & $8,180.5$ (441.5) \\
\hline Georgia & 41 & $65.1(3.0)$ & $46.3(2.8)$ & $28.8(1.0)$ & 28.6 (28.1-29.8) & $17.3(2.4)$ & 6,139.5 (370.2) \\
\hline South Carolina & 42 & $67.0(2.0)$ & $48.9(3.1)$ & $27.0(2.6)$ & 25.8 (24.8-29.8) & $14.8(2.5)$ & 6,972.8 (259.2) \\
\hline West Virginia & 43 & $80.3(2.2)$ & $58.8(2.0)$ & $26.7(2.1)$ & 25.9 (25.4-28.5) & $11.6(4.0)$ & 8,865.8 (494.6) \\
\hline Tennessee & 44 & $75.8(0.8)$ & $57.0(2.0)$ & $24.7(2.8)$ & 23.9 (22.5-27.3) & $12.9(1.8)$ & $7,056.8(260.4)$ \\
\hline Kentucky & 45 & $93.5(2.4)$ & $67.8(2.2)$ & $27.5(0.6)$ & 27.7 (27.0-28.1) & $11.4(3.9)$ & 7,494.5 (377.9) \\
\hline Oklahoma & 46 & $70.5(2.3)$ & $55.7(2.5)$ & $21.0(2.7)$ & 19.5 (19.0-23.7) & $16.8(2.1)$ & 7,254.0 (293.1) \\
\hline Alabama & 47 & $67.8(3.3)$ & $53.5(2.9)$ & $21.2(1.7)$ & 20.9 (19.6-23.0) & $12.7(1.6)$ & 6,909.8 (310.4) \\
\hline Arkansas & 48 & $78.0(1.4)$ & $59.1(2.3)$ & $24.2(3.3)$ & 24.5 (21.0-27.4) & $14.2(3.3)$ & 6,931.5 (348.0) \\
\hline Louisiana & 49 & $68.9(2.4)$ & $53.7(2.5)$ & $22.1(1.5)$ & 21.8 (21.0-23.4) & $15.5(2.3)$ & 7,441.5 (282.5) \\
\hline Mississippi & 50 & $75.0(1.7)$ & $57.5(1.9)$ & $23.4(1.5)$ & 23.7 (22.2-24.4) & $15.8(2.1)$ & 7,302.5 (339.8) \\
\hline
\end{tabular}




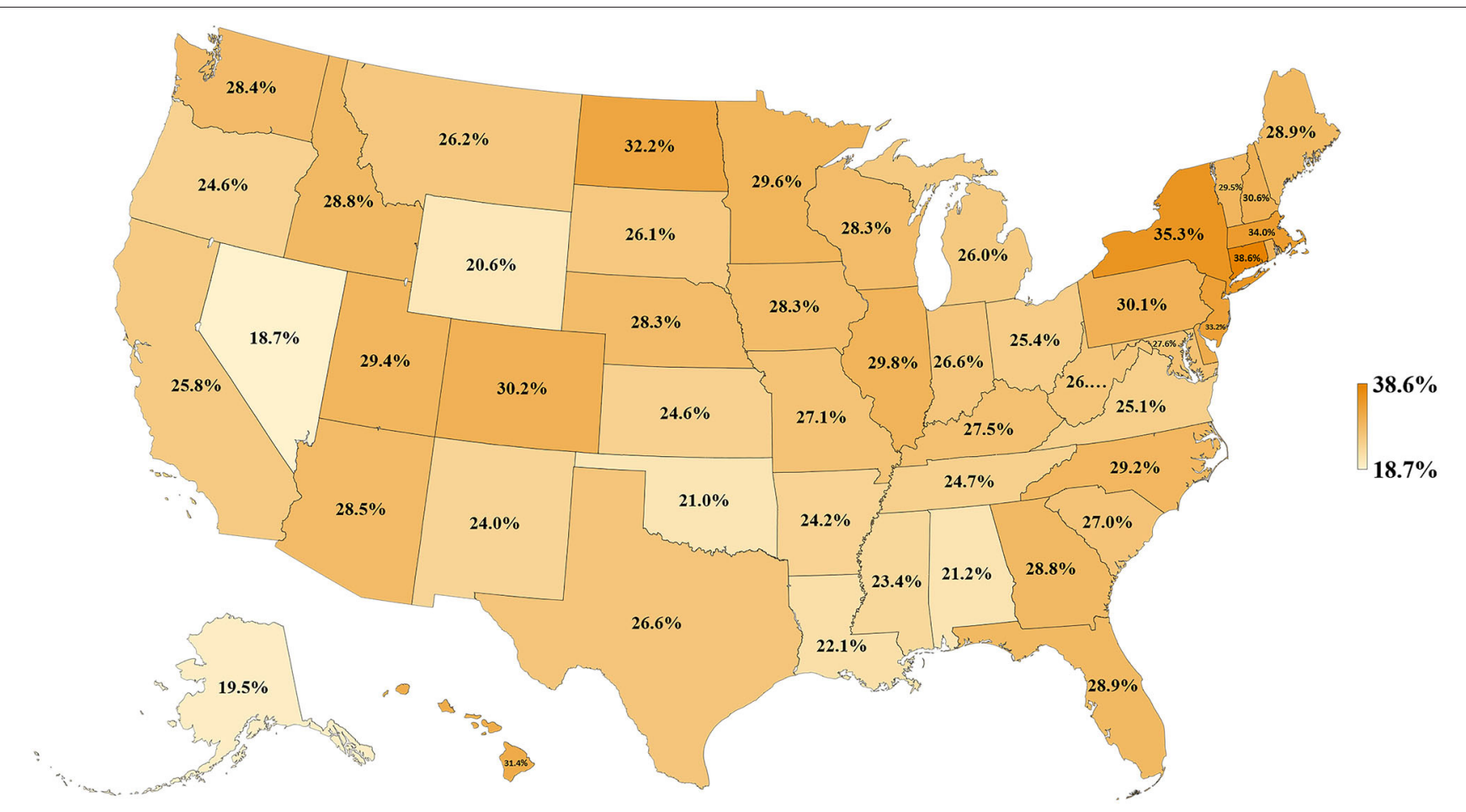

FIGURE 1 | Map of lung cancer CSVs for 50 states of the US, 2011-2015.

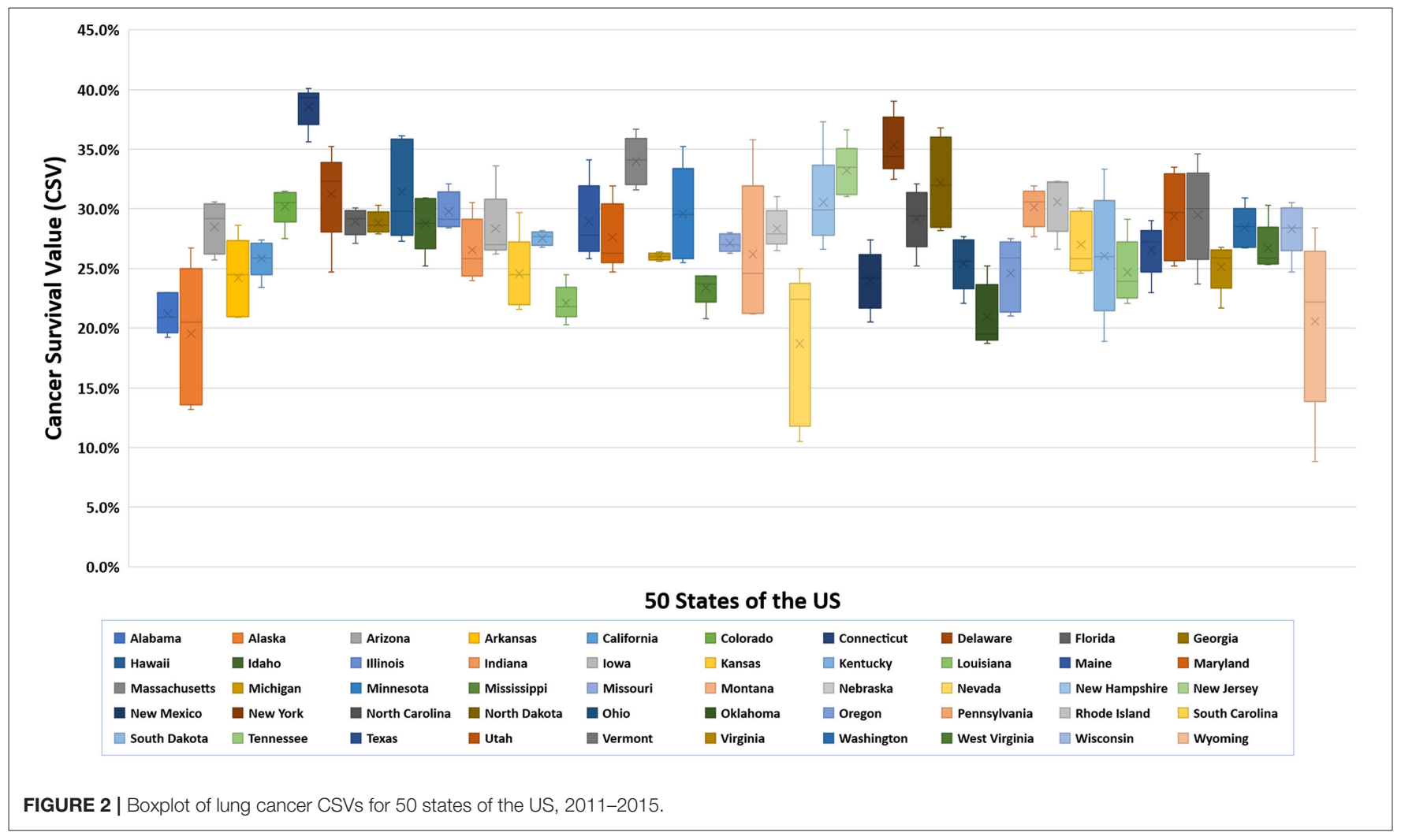



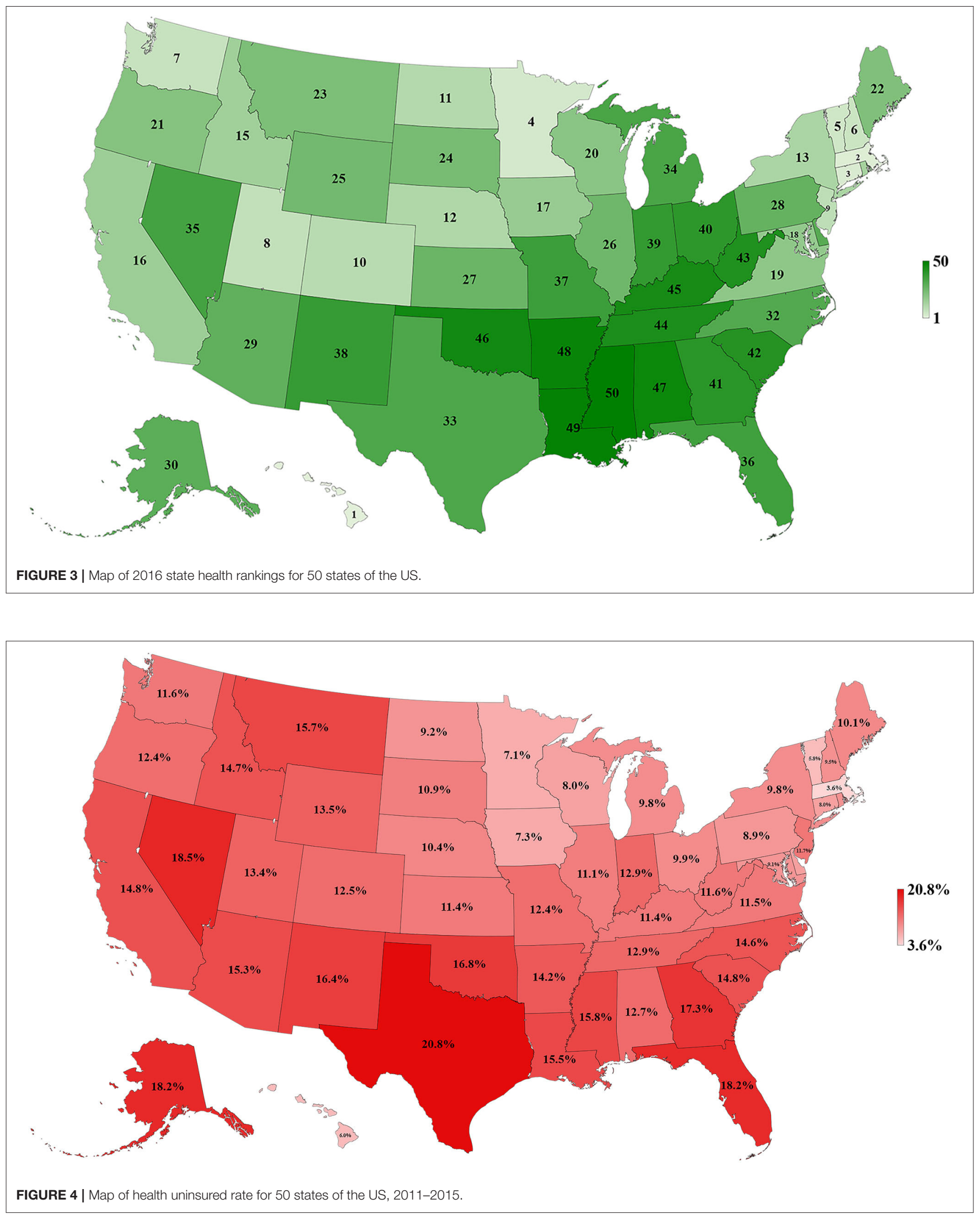


\section{State Health Rankings, Health Uninsured Rate, and Health Spending per Capita Were Significantly Associated With Lung Cancer CSVs}

Table 1 and Figures 3-5 show the differences in health delivery outcomes for the 50 states using the 2016 state health rankings, the 5-year average (2011-2015) of health uninsured rates per state, and the 4-year average (2011-2014) of health spending per capita per state. In regard to state health rankings, Hawaii had the highest health ranking and Mississippi had the lowest health ranking, and it is significantly associated with improved $\operatorname{CSV}\left(R^{2}=0.418, P<0.001\right.$, Figure 6A). The regression formula is $y=-0.0017 x+0.3194$, wherein, for every 1-unit change (worsening) in health system ranking, there is a 0.0017 decrement in the CSV. For health uninsured rate, the highest was Texas $(20.8 \pm 2.5 \%)$ and the lowest was Massachusetts (3.6 $\pm 0.6 \%)$, and it is negatively correlated with $\operatorname{CSV}\left(R^{2}=0.352, P<0.001\right.$, Figure 6B). Massachusetts also had the second highest health spending per capita $(\$ 10,180.3 \pm 313.7$ per year $)$ and Utah had the lowest health spending per capita $(\$ 5,631.0 \pm 268.2$ per year). Health spending is also associated with $\operatorname{CSV}\left(R^{2}=0.142, P=\right.$ 0.007, Figure 6C).

\section{DISCUSSION}

To our knowledge, this is the first study to evaluate the association between lung cancer CSVs and state health delivery variables within the US. This study demonstrates clear geographic variations in lung cancer care outcome rates between states and its marked association with state-level health disparities. The CSV, derived from the validated MIR, is regarded as a valid proxy for 5-year relative survival and an indicator of cancer care delivery outcomes $(14,15)$. Although Ellis et al. recently suggested that MIR should not be used as a proxy of cancer survival in England, their study showed the absolute difference between the CSV and 5-year survival was $<10 \%$ for lung cancer, which is similar to the previous study result in the United States, the Netherlands, and the five Nordic countries $(15,16)$. Therefore, CSV could still be considered as a good approximation of the 5-year relative survival for lung cancer but not all tumor sites. The mapping of lung cancer CSVs shows that the Northeastern states have higher relative lung cancer survival whereas Southern states have lower relative lung cancer survival. Mortality is influenced by early interventions in risk factor reduction (tobacco smoking), early detection with LDCT among smokers, and effective application of state-of-the-art advances in treatment including surgery, focused radiotherapy chemotherapy, targeted drugs, and/or immunotherapy for lung cancer (2-4, 17-21). The variability in health delivery per state, namely, health rankings, uninsured rates, and total health care spending per capita, may reflect variable access to these preventive and therapeutic options leading to clear variability in lung cancer CSV within the country. In our model, total health ranking had the highest $R^{2}$ explaining $42 \%$ of the variability of CSV,

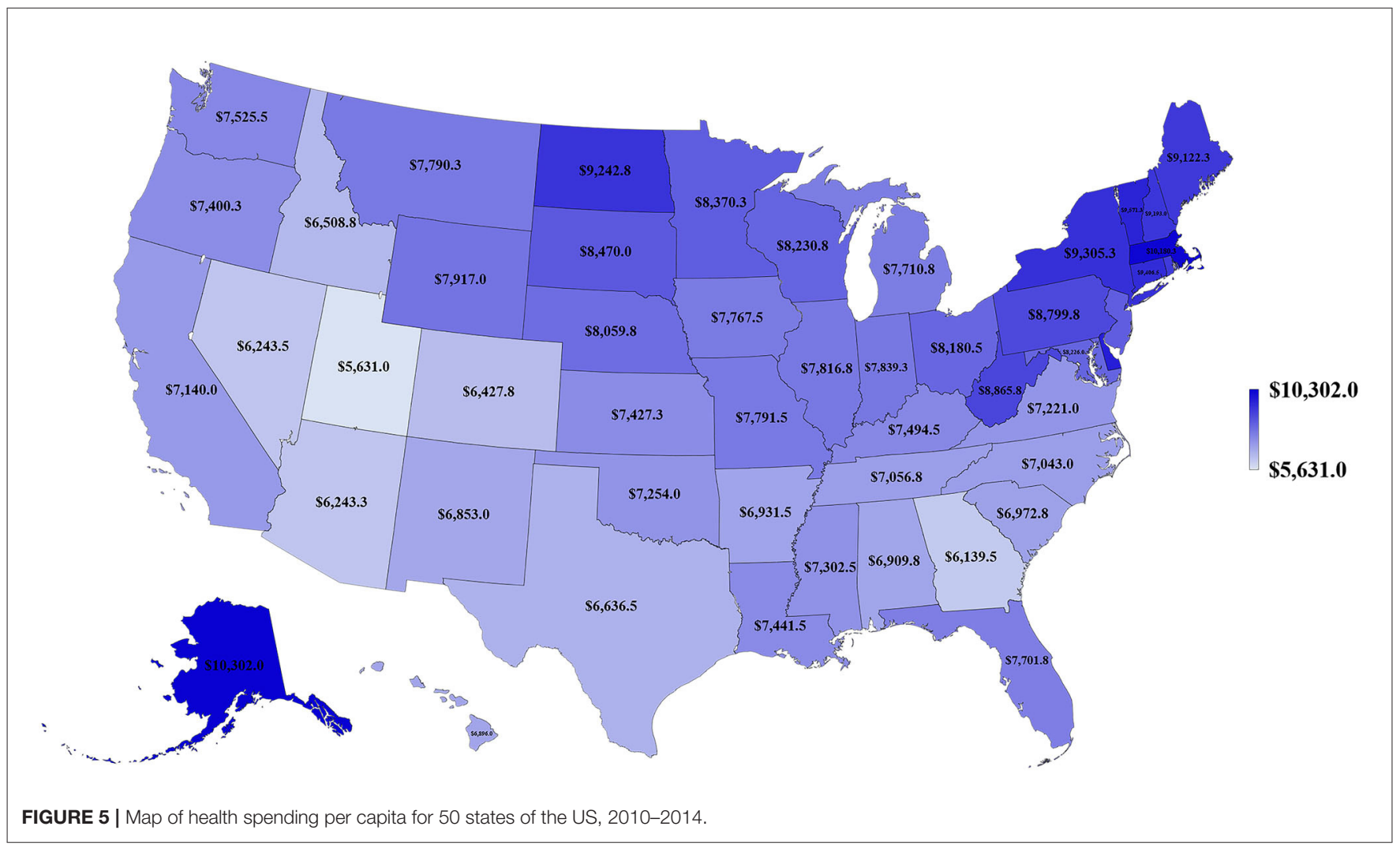



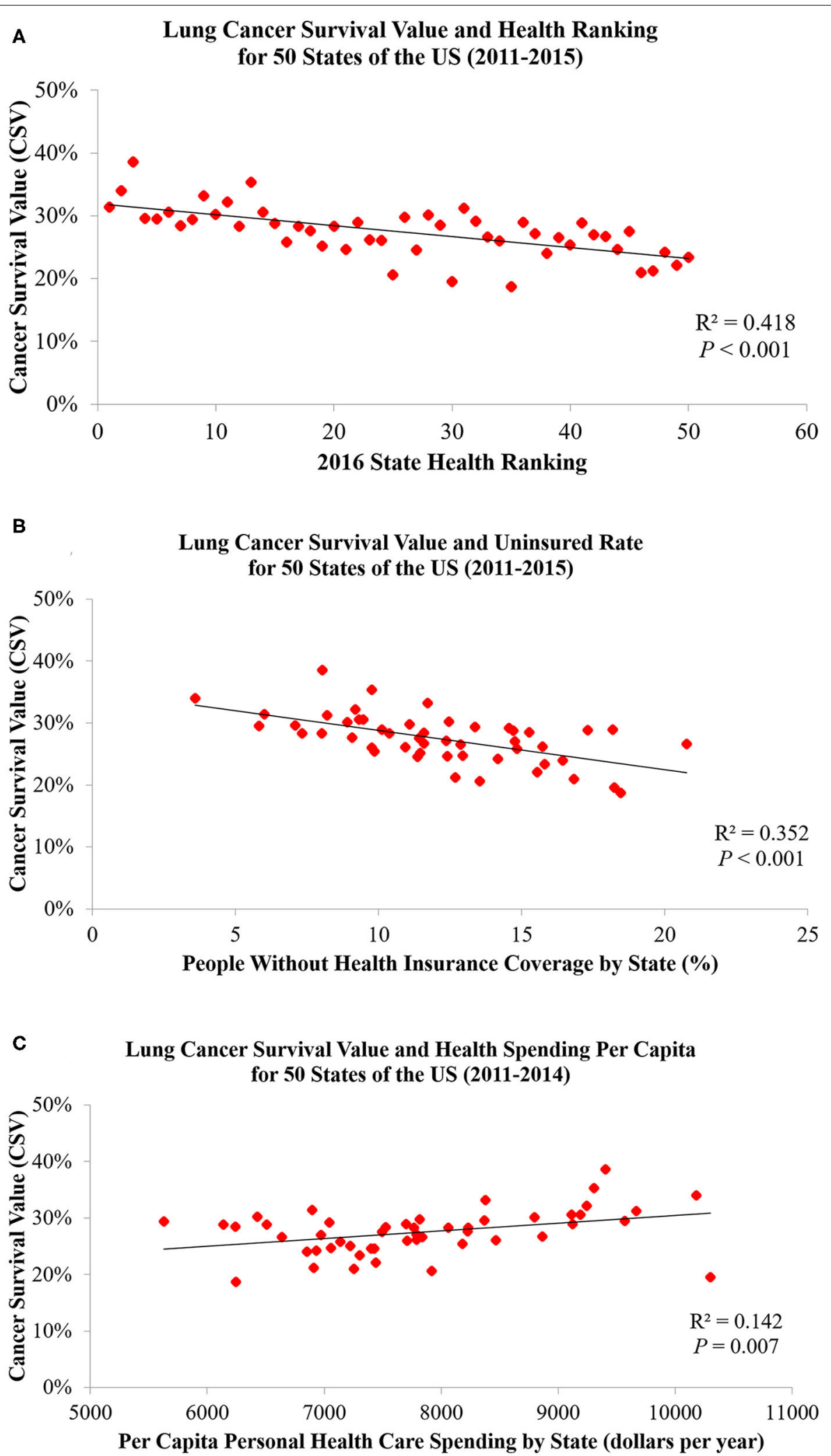

FIGURE 6 | Lung cancer CSVs are significantly associated with (A) state health rankings, (B) health uninsured rates, and (C) health spending per capita. 
followed by uninsured rates (35\%) and health spending per capita (14\%).

The Northeastern states have higher relative lung cancer survival, better health rankings, lower health uninsured rate, and higher health spending per capita compared to the Southern states. This phenomenon can be explained by the similar characteristics among adjacent states, which include the demographics [percentage of total African American population by region according to the 2010 Census: Northwest (17\%), Midwest (18.1\%), South (55.0\%), and West (9.8\%)], numbers of physicians per capita, socioeconomic conditions, the availability of medical services, incomes of residents, and the levels of benefits provided by public and private health programs (2227). Affordability and access to state-of-the art cancer care are important factors for geographic differences of cancer survival. Interestingly, Onega et al. indicated the Northeastern states had the shortest travel times to National Cancer Institute (NCI) Cancer Centers and the highest per capita oncologist supply, followed by the Western, the Midwestern, and then the Southern states (28). This suggested that a better geographic access to cancer care is linked to a significant cancer survival benefit (29).

We found a negative correlation between state health rankings and lung cancer CSVs that is similar to a previous study result on colorectal cancer among the Organization for Economic Co-operation and Development (OECD) countries (11). Sunkara et al. identified a strong relationship between colorectal cancer MIRs and WHO rankings of OECD countries, which suggests that better colorectal cancer survival is highly associated with better quality of cancer screening and health care systems. Similarly, Choi et al. found an important correlation between lung cancer MIR and health care rankings between OECD countries with an $R^{2}$ of 0.32 and 0.49 after removing outliers (9). Therefore, our findings may be a reflection of the profound impact that health policies and delivery at a state level have on clinical outcomes. Early detection and appropriate treatments for lung cancer, including surgical interventions and advanced therapies, lead to large health expenditures (30-32). For example, Vera-Llonch et al. in their study, indicated that health care costs among patients with metastatic lung cancer receiving chemotherapy are substantial, exceeding $\$ 125,000$ per patient over a mean follow-up period of 500 days. This might be the reason that lung cancer CSVs are significantly associated with health uninsured rates and health spending per capita (2).

\section{REFERENCES}

1. Siegel RL, Miller KD, Jemal A. Cancer statistics. CA. (2019) 69:7-34. doi: 10.3322/caac. 21551

2. American Cancer Society. Cancer Facts \& Figures 2019. Atlanta: American Cancer Society (2019).

3. Boloker G, Wang C, Zhang J. Updated statistics of lung and bronchus cancer in United States. J Thoracic Dis. (2018) 10:1158. doi: 10.21037/jtd.2018.03.15

4. Moolgavkar SH, Holford TR, Levy DT, Kong CY, Foy M, Clarke L, et al. Impact of reduced tobacco smoking on lung cancer mortality in the United States during 1975-2000. J Natl Cancer Institute. (2012) 104:541-8. doi: $10.1093 /$ jnci/djs136
There are some limitations to our study. First, no further clinical information including lung cancer types, stages at diagnosis, molecular characteristics, or application of LDCT screening was available to create a comprehensive model. Second, the use of the state health rankings, health uninsured rates, and health spending per capita to represent the health disparities of states are not the only parameters to evaluate the status of health care delivery. We did not have access to the lung cancer risk factors rates, state-specific prevention programs, and other socioeconomic factors of relevance, which may play crucial roles in explaining the incidence and mortality rates. As a result, further investigations with greater detail and data are needed to support our findings.

In conclusion, this study showed that lung cancer CSVs are significantly associated with state health rankings, health uninsured rates, and health spending per capita. These findings suggest that CSVs of lung cancer can be an applicable measure to evaluate and reflect the state-level health disparities in the United States. Our study also provides evidence for policy makers and public health practitioners developing more effective prevention and interventions for lung cancer.

\section{DATA AVAILABILITY STATEMENT}

The raw data supporting the conclusions of this article will be made available by the authors, without undue reservation.

\section{AUTHOR CONTRIBUTIONS}

Y-CL had full access to all of the data in the study and takes responsibility for the integrity of the data and the accuracy of the data analysis. Y-CL and MM contributed to the literature review, study concept and design, data analysis, and interpretation. Y-CL, $\mathrm{RC}-\mathrm{C}, \mathrm{GH}, \mathrm{MC}$, and MM contributed to the writing and revision of the manuscript. All authors contributed to the article and approved the submitted version.

\section{ACKNOWLEDGMENTS}

The authors would like to thank the United States Cancer Statistics, America's Health Rankings, the U.S. Census Bureau, and Centers for Medicare \& Medicaid Services for providing the dataset.

5. Hébert JR, Daguise VG, Hurley DM, Wilkerson RC, Mosley CM, Adams SA, et al. Mapping cancer mortality-to-incidence ratios to illustrate racial and sex disparities in a high-risk population. Cancer. (2009) 115:2539-52. doi: $10.1002 /$ cncr. 24270

6. Lee H-L, Peng C-M, Huang C-Y, Wu SY, Tsai MC, Wang CC, et al. Is mortality-to-incidence ratio associated with health disparity in pancreatic cancer? A cross-sectional database analysis of 57 countries. BMJ Open. (2018) 8:e020618. doi: 10.1136/bmjopen-2017-020618

7. Odahowski CL, Hébert JR, Eberth JM. Regional variation in lung and bronchus cancer survival in the US using mortality-to-incidence ratios. Spatial Spatio-Temporal Epidemiol. (2018) 26:107-12. doi: 10.1016/j.sste.2018. 06.004 
8. Chen S-L, Wang S-C, Ho C-J, Kao YL, Hsieh TY, Chen WJ, et al. Prostate cancer mortality-to-incidence ratios are associated with cancer care disparities in 35 countries. Sci Rep. (2017) 7:40003. doi: 10.1038/srep40003

9. Choi E, Lee S, Nhung BC, Suh M, Park B, Jun JK, et al. Cancer mortality-to-incidence ratio as an indicator of cancer management outcomes in Organization for Economic Cooperation and Development countries. Epidemiol Health. (2017) 39:e2017006. doi: 10.4178/epih.e2017006

10. Sung W-W, Wang S-C, Hsieh T-Y, Huang CY, Kao YL, Chen WJ, et al. Favorable mortality-to-incidence ratios of kidney Cancer are associated with advanced health care systems. BMC Cancer. (2018) 18:792. doi: 10.1186/s12885-018-4698-6

11. Sunkara V, Hébert JR. The colorectal cancer mortality-to-incidence ratio as an indicator of global cancer screening and care. Cancer. (2015) 121:1563-9. doi: $10.1002 /$ cncr. 29228

12. Tsai M-C, Wang C-C, Lee H-L, Peng CM, Yang TW, Chen HY, et al. Health disparities are associated with gastric cancer mortality-toincidence ratios in 57 countries. World J Gastroenterol. (2017) 23:7881-7. doi: 10.3748/wjg.v23.i44.7881

13. Berchick ER, Hood E, Barnett JC. Health Insurance Coverage in the United States: 2017. Current Population Reports. US Government Printing Office, Washington, DC (2018). p. 60-264.

14. Stenning-Persivale K, Franco MJS, Cordero-Morales A, Cruzado-Burga J, Poquioma E, Díaz Nava E, et al. The mortality-incidence ratio as an indicator of five-year cancer survival in metropolitan Lima. Ecancermed Sci. (2018) 12:799. doi: 10.3332/ecancer.2018.799

15. Asadzadeh Vostakolaei F, Karim-Kos HE, Janssen-Heijnen ML, Visser O, Verbeek AL, Kiemeney LA. The validity of the mortality to incidence ratio as a proxy for site-specific cancer survival. Eur J Public Health. (2010) 21:573-77. doi: 10.1093/eurpub/ckq120

16. Ellis L, Belot A, Rachet B, Coleman MP. The mortality-to-incidence ratio is not a valid proxy for cancer survival. J Glob Oncol. (2019) 5:1-9. doi: 10.1200/JGO.19.00038

17. Cheung LC, Katki HA, Chaturvedi AK, Jemal A, Berg CD. Preventing lung cancer mortality by computed tomography screening: the effect of riskbased versus US Preventive Services Task Force eligibility criteria, 2005-2015. Annals Internal Med. (2018) 168:229-32. doi: 10.7326/M17-2067

18. Team NLSTR. Reduced lung-cancer mortality with low-dose computed tomographic screening. N Engl J Med. (2011) 365:395-409. doi: 10.1056/NEJMoa1102873

19. Wender R, Fontham ET, Barrera E Jr, Colditz GA, Church TR, Ettinger DS, et al. American Cancer Society lung cancer screening guidelines. CA. (2013) 63:106-17. doi: 10.3322/caac. 21172

20. Alberg AJ, Samet JM. Epidemiology of lung cancer. Chest. (2003) 123:21S-49S. doi: 10.1378/chest.123.1_suppl.21S

21. General S. The Health Consequences of Smoking-50 Years of Progress: A Report of the Surgeon General. Paper presented at: US Department of Health and Human Services (2014).

22. Cooper RA. States With More Physicians Have Better-Quality Health Care: At the state level, increased numbers of both family physicians and specialists per capita are associated with higher quality of health care. Health Affairs. (2008) 27(Suppl1):w91-102. doi: 10.1377/hlthaff.28.1.w91

23. Dickman SL, Himmelstein DU, Woolhandler S. Inequality and the health-care system in the USA. Lancet. (2017) 389:1431-41. doi: 10.1016/S0140-6736(17)30398-7

24. Joseph TD, Marrow HB. Health Care, Immigrants, and Minorities: Lessons From the Affordable Care Act in the US. Taylor \& Francis (2017). doi: 10.1080/1369183X.2017.1323446

25. Kates J. Implications of the affordable care act for people with HIV infection and the Ryan White HIV/AIDS Program: what does the future hold? Top Antiviral Med. (2013) 21:138.

26. Lynch J, Harper S, Kaplan GA, Davey Smith G. Associations between income inequality and mortality among US states: the importance of time period and source of income data. Am J Public Health. (2005) 95:1424-30. doi: 10.2105/AJPH.2004.048439

27. Travis R, Morris JC, Mayer M, Kenter R, Breaux DA. Explaining state differences in the implementation of the patient protection and affordable care act: a south/Non-South comparison. Soc Sci Quart. (2016) 97:573-87. doi: $10.1111 /$ ssqu. 12297

28. Onega T, Duell EJ, Shi X, Wang D, Demidenko E, Goodman D. Geographic access to cancer care in the US. Cancer. (2008) 112:909-18. doi: $10.1002 / \mathrm{cncr} .23229$

29. Onega T, Duell EJ, Shi X, Demidenko E, Gottlieb D, Goodman DC. Influence of NCI cancer center attendance on mortality in lung, breast, colorectal, and prostate cancer patients. Med Care Res Rev. (2009) 66:542-60. doi: 10.1177/1077558709335536

30. Gonzales S, Cox C, Jankiewicz A, Rousseau D. A snapshot of cancer spending and outcomes. JAMA. (2016) 315:2512. doi: 10.1001/jama.201 6.7250

31. Souliotis K, Kani C, Marioli A, Kamboukou A, Prinou A, Syrigos K, et al. End-of-life health-care cost of patients with lung cancer: a retrospective study. Health Services Res Managerial Epidemiol. (2019) 6:2333392819841223. doi: 10.1177/2333392819841223

32. Vera-Llonch $\mathrm{M}$, Weycker D, Glass A, Gao S, Borker R, Barber $B$, et al. Healthcare costs in patients with metastatic lung cancer receiving chemotherapy. BMC Health Services Res. (2011) 11:305. doi: 10.1186/1472-6963-11-305

Conflict of Interest: The authors declare that the research was conducted in the absence of any commercial or financial relationships that could be construed as a potential conflict of interest.

Copyright (C) 2020 Lee, Calderon-Candelario, Holt, Campos and Mirsaeidi. This is an open-access article distributed under the terms of the Creative Commons Attribution License (CC BY). The use, distribution or reproduction in other forums is permitted, provided the original author(s) and the copyright owner(s) are credited and that the original publication in this journal is cited, in accordance with accepted academic practice. No use, distribution or reproduction is permitted which does not comply with these terms. 